\title{
An appraisal of blood pressure control and its determinants among patients with primary hypertension seen in a primary care setting in Western Nigeria
}

\author{
Oluwaseun S Ojo ${ }^{a *}$, Sunday O Malomo ${ }^{\mathrm{iD}}$, Peter T Sogunle ${ }^{\mathrm{i}}$ and Adegbola M Ige ${ }^{\mathrm{a}}$ \\ ${ }^{a}$ Department of Family Medicine, Federal Medical Centre, Abeokuta, Nigeria \\ *Corresponding author, email:ojo_teenager@yahoo.com
}

Background: Achieving guideline-recommended blood pressure is imperative in reducing the rising tide of uncontrolled hypertension and its attendant sequelae, which are major causes of morbidity and mortality globally. The aim of the study was to describe the pattern of blood pressure control and identify the factors influencing blood pressure control among patients with primary hypertension seen at family medicine clinics of FMC, Abeokuta.

Methods: This was a descriptive cross-sectional hospital-based study. A systematic random sampling technique was used in selecting 360 hypertensive respondents over four months. Data were collected through a pre-tested interviewer-administered questionnaire. The Statistical Package for the Social Sciences (SPSS) version 17.0 was used to analyse data.

Results: Blood pressure was controlled in $167(46.4 \%)$ of the respondents. The independent predictors of blood pressure control were female gender $(p=0.001, \mathrm{OR}=2.494,95 \%$ confidence interval $(\mathrm{Cl})=1.477-4.214)$, regular use of medication $(p=0.001, \mathrm{OR}$ $=2.900,95 \% \mathrm{Cl}=1.508-5.577)$, regular clinic attendance $(p<0.001, \mathrm{OR}=3.512,95 \% \mathrm{Cl}=1.772-6.960)$, and absence of diabetes mellitus $(p<0.001, \mathrm{OR}=7.357,95 \% \mathrm{Cl}=3.190-16.966)$.

Conclusions: The rate of blood pressure control among the hypertensive respondents was low. Multiple independent predictors of controlled blood pressure call for a team-based approach as well as multiple approaches including education of patients, expansion of a community-based health insurance programme and intensification of treatment efforts when managing hypertensive patients.

Keywords: blood pressure control, family medicine clinics, primary hypertension

\section{Introduction}

Hypertension is a major public health problem globally with a greater population burden in developing than developed countries. ${ }^{1,2}$ In developed countries, only $7 \%$ of deaths under the age of 60 are caused by uncontrolled hypertension and its complications, while this increases to $25 \%$ in the African region. ${ }^{3}$ In a multi-centre study of cardiovascular diseases in Nigeria, hypertension ranked first and its complications constituted $25 \%$ of medical admissions in urban hospitals in the country. ${ }^{4}$

The goal of therapy is to normalise blood pressure (BP) and prevent cardiovascular events. However, in clinical practice, recommended BP is sometimes difficult to achieve. ${ }^{1,5}$ An Internet search on analysis of BP control showed poor control rates in most countries with the highest rate of $51.8 \%$ noted in Hong Kong. ${ }^{5}$ The growing problem of inadequate BP control is not different in Nigeria. Poor BP control of less than $50 \%$ is consistent in most studies. ${ }^{6-8}$ Therefore, understanding the factors associated with uncontrolled hypertension could help improve patients' care by finding an effective way of addressing these barriers, and hence reduce the burden on the health facility, family and individual.

Most tertiary health centre based studies on BP control in Nigeria were carried out in the cardiology clinic. ${ }^{6-9}$ The few tertiary health centre based studies done in the family medicine clinic recruited patients only from the General Outpatient Clinic (GOPC). ${ }^{10,11}$ With the advent of the National Health Insurance Scheme (NHIS) in Nigeria, most family medicine departments in our tertiary hospital attend to NHIS patients at the NHIS clinic. There is no tertiary health centre based study done in the family medicine department on BP control that recruited NHIS patients. It is against this background that the researchers were motivated to study BP control and its determinants among adults with primary hypertension in a family medicine clinic comprising of out-ofpocket patients and insurance patients (NHIS).

\section{Subjects and methods Study setting}

Abeokuta is the capital of Ogun state in South West Nigeria. As of 2005, Abeokuta and the surrounding area had a population of $593,140 .{ }^{12}$ The city is known for its traditional style of hand-woven cotton cloth known as 'adire', which is dyed with locally produced indigo. The Federal Medical Centre, Abeokuta is a tertiary institution with a tripartite mandate of training and research, and service delivery. It also serves as a referral centre for primary and secondary public health institutions as well as missionary and private hospitals in Ogun state, and neighbouring south-western states of Nigeria. The family medicine clinics comprising the general outpatient clinic (GOPC), corporate clinic (COOP) and National Health Insurance Scheme clinic (NHIS) are the primary care clinics of the hospital. Patients that are seen at the GOPC buy their drugs out of pocket. Members of staff of the hospital and well-to-do members of the public are seen at the COOP clinic. All members of staff seen at the COOP clinic are enrolled under the NHIS while the members of the public seen at the COOP clinic buy their drugs out of pocket. Members of the public who enrolled under the NHIS are seen at the NHIS clinic. The clinics are run by consultant family physicians and postgraduate resident doctors in family medicine.

\section{Study design}

This study was a hospital-based, cross-sectional descriptive study conducted on 360 adults aged 18 and above with primary 
hypertension who attended the GOPC, COOP and NHIS clinics of FMC, Abeokuta between May and July 2013. The estimated population per year based on the number of adult patients with essential hypertension (cases) that attended the three clinics in 2011 was 2982. The GOPC, NHIS and COOP clinics had 1502 (50.4\%), 836 (28.0\%) and $644(21.6 \%)$ attendees respectively.

\section{Inclusion criteria}

(1) Patients aged 18 years and above with essential hypertension.

(2) Patients with essential hypertension who had been on outpatient treatment for hypertension in the clinic for at least one year.

\section{Exclusion criteria}

(1) Patients with secondary hypertension.

(2) Patients with major psychiatric illness.

(3) Patients with a severe illness that makes it difficult to follow the study protocol.

\section{Sample size determination}

The sample size $(n)$ was calculated using the formula ${ }^{13} n=z^{2} p q /$ $d^{2}$. At $95 \%$ confidence interval and a precision level of $5 \%$, $z=1.96$ and $d=0.05$. The proportion of hypertensive patients with controlled blood pressure (p) was 39\% from previous study. ${ }^{14}$ Therefore, $p=0.39$ and $q=1-0.39=0.61$. Then, $(\mathrm{n})=1.96^{2} \times 0.39 \times 0.61 / 0.05^{2}=365.6$.

Since the number of patients with essential hypertension (N) that attended the three clinics in 2011 was 2982 (less than $10,000)$, the sample size was adjusted by the formula ${ }^{13} \mathrm{nfn} /$ $(1+n / N)$. Thus, $n f=365.6 /(1+365.6 / 2,982)=325.7$, which is approximately 326 .

The minimum sample size was 326 . However, $10 \%$ of the total sample size was added to the minimum sample size to improve the power of the study. This gave a sample size of 360 respondents.

\section{Sampling technique}

Proportionate sampling was predetermined for each clinic (180 for GOPC, 100 for NHIS and 80 for COOP) representing 50.4\%, $28.0 \%$ and $21.6 \%$ respectively of 360 (the sample size). A systematic random sampling technique was utilised to select 360 hypertensive patients from the three clinics. The total number of adult patients with essential hypertension that attended the three clinics in 2011 was 2982. This translated to 960 estimated respondents in four months of data collection. The sampling interval ' $k$ ' was calculated thus; $k N / n$ where ' $n$ ' is the sample size (360), and ' $\mathrm{N}$ ' is the estimated population size within the study period $(960) \mathrm{K}=960 / 3602.67 \approx 3$. The first person was selected from the first three patients with essential hypertension arriving at each clinic by simple random sampling (balloting) once at the outset of the study. Thereafter, every consenting third person was recruited until the required number ( 180 for the GOPC, 100 for the NHIS clinic and 80 for the COOP clinic) was achieved.

\section{Data collection tool and process}

Eligibility for the study was determined and consent (Appendix I) was taken. Data were collected by the principal investigator and two trained research assistants (resident doctors in the Department of Family Medicine, FMC, Abeokuta) through interview using a pretested questionnaire (Appendix II). The pretesting of the questionnaire was conducted on 25 hypertensive patients who were selected haphazardly from the GOPC of Sacred Heart Hospital, Lantoro and it lasted for 2 days. The pretesting was done to find out how the questionnaire would interact with the respondents and ensured that there were no ambiguities. Necessary adjustment was made after the pretest.

The pretested questionnaire Appendix II consisted of four sections: socio-demographic variables, social history, clinical factors and physical examination. It extracted information regarding patients' demographic factors, level of education, average monthly earnings, family history of hypertension, clinic attendance, self-reported use of antihypertensive medications, practice of exercise, co-morbid conditions like asthma and diabetes mellitus and patients' knowledge about hypertension.

To assess respondents' knowledge about hypertension, participants' idea of hypertension, its cause, duration of treatment, what blood pressure control entails and the consequences of lack of consistent blood pressure control were assessed. There were 11 questions on patients' knowledge about hypertension in the predesigned questionnaire. Adequate response to each question was scored as 1 . A total score of greater than or equal to 7 was considered to be good knowledge of hypertension while a score of $\leq 6$ was considered poor knowledge.

Assessment of practice of exercise was self-reported. Participants were considered to engage in exercise if he or she said yes to the question 'Do you exercise?'. Practice of exercise was regarded to be adequate if the respondent engaged in exercise at the recommended frequency (at least 3 times in a week and for more than 30 minutes during each session). Adherence to medication was obtained from each respondent through self-report. It was regarded as 'regular' if the respondent said yes to the question 'Do you take your drugs regularly?'. Adherence to clinic attendance was regarded as 'poor' if respondents had failed to keep a clinic appointment at least once in the previous six months. Participants were regarded as having diabetes mellitus if they had been diagnosed previously by a doctor or if they were receiving insulin or oral antidiabetic medications.

Blood pressure measurement for each subject was taken in the clinic using an Accosson mercury sphygmomanometer (AC Cossor \& Son (Surgical) Ltd. London, England) after subjects had rested for five minutes. Systolic blood pressure (SBP) and diastolic blood pressure (DBP) were measured at Korotkoff phases I and V respectively. ${ }^{15}$ The average of two blood pressures taken in the sitting position at intervals of two minutes was added to two previous blood pressure readings in the last two visits within the last six months from the patients' record. The average of the three blood pressure readings was used as an indication of level of control. ${ }^{16}$ Blood pressure greater than or equal to $140 / 90 \mathrm{mmHg}$ in non-diabetics and greater than or equal to $130 / 80 \mathrm{mmHg}$ in diabetics was classified as uncontrolled. ${ }^{17}$

The waist circumference was measured with a tape measure as the horizontal circumference midway between the lowest rib and the iliac crest at the end of a normal expiration. The measurement was repeated twice and the average of the two measurements obtained was calculated if they were within one centimetre of one another. When the difference between the two measurements exceeded $1 \mathrm{~cm}$, the two measurements were 
repeated. A waist circumference of more than 40 inches $(102 \mathrm{~cm})$ in men and greater than 35 inches $(88 \mathrm{~cm})$ for women was considered abnormal. ${ }^{18}$

\section{Statistical analysis}

Data were entered into the Statistical Package for Social Sciences ${ }^{\circledR}$ (SPSS Inc., Chicago, USA) version 17.0 program. Continuous variables were summarized as mean and standard deviation while categorical variables were summarised as percentages. BP control was the main outcome (dependent) variable, while socio-demographic characteristics and clinical factors were the independent variables. A chi-square test was used to determine the association between BP control and the various independent variables. The level of significance was set at a $p$-value of less than or equal to 0.05 and a confidence interval (Cl) of $95 \%$. Logistic regression analysis was used to identify the independent predictors of $\mathrm{BP}$ control. The odds ratios (OR) and $95 \%$ confidence intervals $(95 \% \mathrm{Cl})$ for the predictor variables were then calculated.

\section{Ethical consideration}

Ethical approval was obtained from the Ethics Committee of the hospital. Informed consent was also obtained from the respondents included in the study.

\section{Results}

A total of 360 randomly selected hypertensive patients were studied. The age range of the respondents was 35-84 years. They were mainly in the middle age group ( $n=220$ [61.1\%]) with a mean age of $55.4 \pm 10.5$. There were more female $(n=214$ [59.4\%]) than male $(n=146$ [40.6\%]) respondents with a male-tofemale ratio of 1:1.5.

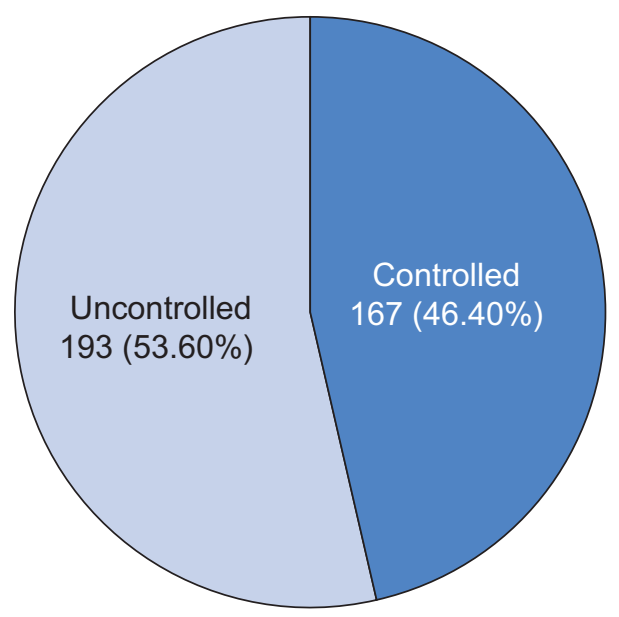

Figure 1: Pattern of blood pressure control among respondents.
Two hundred and sixteen ( $n=216$ [60\%]) respondents reported that they took their drugs regularly. The percentage of respondents that reported regular use of their antihypertensive medications in the GOPC, COOP and NHIS clinics were $50 \%$, $68.8 \%$ and $71.0 \%$ respectively. The proportion of respondents that attested to practising any form of exercise was $36.9 \%$ (133) and less than half of them exercised at the recommended frequency (at least 3 times in a week and for more than 30 minutes per session). Among the studied participants, 49 (13.6\%) respondents had co-morbid diabetes mellitus. Only one-third of the respondents $(n=120$ [33.3\%]) had health insurance.

Using the average BP as explained in the methodology, the mean systolic BP (SBP) in the study population was $138.8 \pm 17.2 \mathrm{mmHg}$ while mean diastolic BP (DBP) was $84.1 \pm 9.7 \mathrm{mmHg}$. One hundred and sixty-seven (46.4\%) respondents achieved target $\mathrm{BP}(\mathrm{BP}<140 / 90 \mathrm{mmHg}$ in non-diabetics and $\mathrm{BP}<130 / 80 \mathrm{mmHg}$ in diabetics) while this was not achieved in 193 (53.6\%) respondents (Figure 1).

The number of the respondents who achieved control (SBP and DBP within normal range) in the GOPC, NHIS and COOP clinics was $69(38.3 \%), 53(53.0 \%)$ and $45(56.3 \%)$ respectively (Table 1$)$.

There was a significant association between BP control and gender $\left(\chi^{2}=5.332, p=0.021\right)$, self-report on use of medication $\left(\chi^{2}\right.$ $=56.361, p<0.001)$, clinic attendance $\left(\chi^{2}=57.741, p<0.001\right)$ diabetes mellitus $\left(\chi^{2}=17.908, p<0.001\right)$ and type of clinic attended by respondents $\left(x^{2}=9.582, p=0.008\right)$ (Tables 2 and 3 ).

The independent predictors of controlled BP after logistic regression analysis were female gender $(p=0.001, \mathrm{OR}=2.49$, $95 \% \mathrm{Cl}=1.48-4.21)$, regular use of medications ( $p=0.001$, $\mathrm{OR}=2.90,95 \% \mathrm{Cl}=1.51-5.58)$, regular clinic attendance $(p<0.001, \mathrm{OR}=3.51,95 \% \mathrm{Cl}=1.77-6.96)$, and absence of diabetes mellitus $(p<0.001, \mathrm{OR}=7.36,95 \% \mathrm{Cl}=3.19-16.97)$ (Table 4).

\section{Discussion}

The BP control rate of $46.4 \%$ is high when compared with the rates reported in various Nigerian studies. ${ }^{6,8,19}$ Suboptimal control rates of $36 \%$ in Ibadan, South West Nigeria, ${ }^{19} 24.2 \%$ in Portharcourt, South South Nigeria ${ }^{6}$ and $12.4 \%$ in Zaria, Northern Nigeria $^{8}$ have been reported. All studies mentioned above recruited respondents from the cardiology clinic. The observed difference could be attributed to the fact that patients with complicated and secondary hypertension who are likely to have difficult BP control are likely to be seen in this clinic when compared with primary care clinic. A study in Ilorin, South West Nigeria, ${ }^{7}$ however, reported a higher control rate of $53.3 \%$. The higher BP control rate in the later study might be due to the different definition of controlled BP in this index study and the

Table 1: Comparison of blood pressure control in the three clinics

\begin{tabular}{lccc}
\hline Variable & GOPC & NHIS & COOP \\
& Frequency (\%) & Frequency (\%) & Frequency (\%) \\
& N180 & N100 & N80 \\
\hline SBP and DBP controlled & $69(38.3)$ & $53(53.0)$ & $45(56.3)$ \\
SBP and DBP uncontrolled & $72(40.0)$ & $27(27.0)$ & $16(23.8)$ \\
DBP uncontrolled & $1(0.6)$ & $10(10.0)$ & $118(32.8)$ \\
SBP uncontrolled & $38(21.1)$ & $10(10.0)$ & $17(4.7)$ \\
Total & 180 & 100 & $58(16)$ \\
\hline
\end{tabular}


Table 2: Relationship between blood pressure control and socio-demographic factors

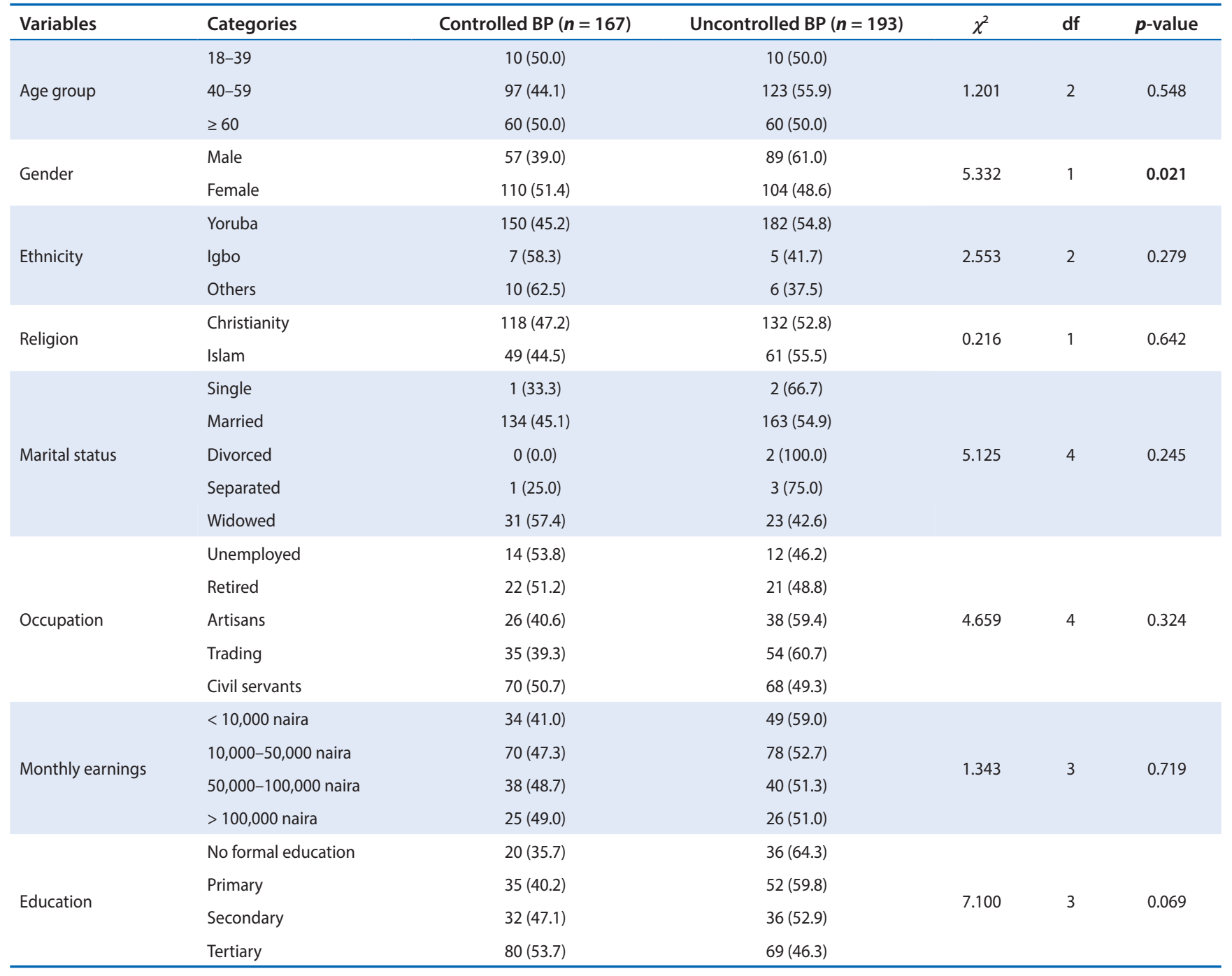

There was a significant association between BP control and gender.

Ilorin study. The use of the higher BP cut-off of 140/90 mmHg for controlled blood pressure among hypertensive-diabetics in the llorin study may explain this difference.

The BP control rate among patients recruited from the GOPC was low (38.3\%) when compared with the NHIS clinic (53.0\%) and COOP clinic (56.3\%). The reasons for this may be due to the highly subsidised drugs that NHIS clinic and some COOP clinic respondents get through health insurance. Second, hypertensive members of staff of the hospital, who are expected to be health conscious, are seen at the COOP clinic. Lastly, patients recruited from the NHIS and COOP clinics had better medication adherence than GOPC patients in this study. Hypertensive patients with access to health insurance had been shown to have better medication adherence and BP control.20,21

A control rate of $53 \%$ among respondents recruited from the NHIS is still inadequate considering the fact that respondents from this clinic had access to highly subsidised medications. This finding of suboptimal control rate in spite of highly subsidised drugs is in consonance with finding from a previous Nigerian study, ${ }^{19}$ which also showed poor control rate (36\%) among hypertensive patients studied despite availability of free drugs. This implies that factors other than poverty might be much important in BP control. Physicians who manage hypertension should pay attention to adequate dosing, appropriate drug combinations and patients' adherence to therapeutic plans.

Female respondents were 2.5 times more likely to have their BP controlled than male respondents $(p=0.001, \mathrm{OR}=2.494,95 \% \mathrm{Cl}$ $=1.477-4.214)$. This is in keeping with the reports from previous studies where BP control has been shown to be better in female respondents. ${ }^{19,22,23}$ This is perhaps because women are more likely to get treated and adhere to therapeutic plans than men. ${ }^{24,25}$

Respondents who used their medications regularly had approximately threefold higher odds of having their BP controlled $(p=0.001, \mathrm{OR}=2.900,95 \% \mathrm{Cl}=1.508-5.577)$. This result supports the existing body of knowledge that regular use of antihypertensive medications positively impacts on BP control. ${ }^{10,26}$ Of interest, one Nigerian study that excluded hypertensive patients with poor drug compliance still reported a BP control rate of $24.2 \%{ }^{6}$ This may suggests that adherence to medications, though important, cannot be a lone factor. It is thus necessary to consider patient, physician and health facility related barriers to optimal BP control when managing these patients.

Hypertensive respondents who attended for follow-up regularly had a 3.5-fold higher odds of having their BP controlled ( $p<$ $0.001, \mathrm{OR}=3.512, \mathrm{Cl}=1.772-6.960)$. This association is expected 
Table 3: Relationship between blood pressure control and clinical factors

\begin{tabular}{|c|c|c|c|c|c|c|}
\hline Variables & Categories & Controlled BP $(n=167)$ & Uncontrolled BP $(n=193)$ & $\chi^{2}$ & df & $p$-value \\
\hline \multirow{3}{*}{ Duration of hypertension } & $\leq 5$ years & $100(44.4)$ & $125(55.6)$ & \multirow{3}{*}{3.779} & \multirow{3}{*}{2} & \multirow{3}{*}{0.151} \\
\hline & $6-10$ years & $39(44.3)$ & $49(55.7)$ & & & \\
\hline & $\geq 11$ years & $28(59.6)$ & $19(40.4)$ & & & \\
\hline \multirow{2}{*}{ Current alcohol consumption } & Yes & $10(35.7)$ & $18(64.3)$ & \multirow{2}{*}{1.391} & \multirow{2}{*}{1} & \multirow{2}{*}{0.238} \\
\hline & No & $157(47.3)$ & $175(52.7)$ & & & \\
\hline \multirow{2}{*}{ Practice of exercise } & Yes & $65(48.9)$ & $68(51.1)$ & \multirow{2}{*}{0.523} & \multirow{2}{*}{1} & \multirow{2}{*}{0.470} \\
\hline & No & $102(44.9)$ & $125(55.1)$ & & & \\
\hline \multirow{2}{*}{ Self-report on use of medication } & Regular & $135(62.5)$ & $81(37.5)$ & \multirow{2}{*}{56.361} & \multirow{2}{*}{1} & \multirow{2}{*}{$<0.001$} \\
\hline & Not regular & $32(22.2)$ & $112(77.8)$ & & & \\
\hline \multirow{2}{*}{ Clinic attendance } & Regular & $135(62.8)$ & $80(37.2)$ & \multirow{2}{*}{57.741} & \multirow{2}{*}{1} & \multirow{2}{*}{$<0.001$} \\
\hline & Not regular & $32(22.1)$ & $113(77.9)$ & & & \\
\hline \multirow{2}{*}{ Health insurance } & Yes & $62(51.7)$ & $58(48.3)$ & \multirow{2}{*}{2.016} & \multirow{2}{*}{1} & \multirow{2}{*}{0.156} \\
\hline & No & $105(43.8)$ & $135(56.2)$ & & & \\
\hline \multirow{2}{*}{ Family history of Hypertension } & Yes & $62(44.6)$ & $77(55.4)$ & \multirow{2}{*}{0.290} & \multirow{2}{*}{1} & \multirow{2}{*}{0.590} \\
\hline & No & $105(47.5)$ & $116(52.5)$ & & & \\
\hline \multirow{2}{*}{ Diabetes mellitus } & Yes & $9(18.4)$ & $40(81.6)$ & \multirow{2}{*}{17.908} & \multirow{2}{*}{1} & \multirow{2}{*}{$<0.001$} \\
\hline & No & $158(50.8)$ & $153(49.2)$ & & & \\
\hline \multirow{2}{*}{ Knowledge about hypertension } & Good & $97(50.5)$ & $95(49.5)$ & 2021 & & 00 \\
\hline & Poor & $70(41.7)$ & $98(58.3)$ & 2.027 & 1 & ל כל \\
\hline W & $<$ recommended & $82(46.3)$ & $95(53.7)$ & Pी०1 & & ר007 \\
\hline valat cilcuminerentice & $>$ recommended & 85 (46.4) & $98(53.6)$ & 0.001 & 1 & 0.902 \\
\hline & GOPD & $69(38.3)$ & $111(61.7)$ & & & \\
\hline Clinic attended & NHIS & $53(53.0)$ & $47(47.0)$ & 9.582 & 2 & 0.008 \\
\hline & COOP & $45(56.3)$ & $35(43.7)$ & & & \\
\hline
\end{tabular}

There was a significant association between BP control and self-report on use of medication, clinic attendance, diabetes mellitus and the type of clinic attended.

Table 4: Logistic regression analysis of significant factors associated with blood pressure control

\begin{tabular}{|c|c|c|c|c|c|}
\hline Variable & Categories & Beta & $p$-value & Odd ratio (OR) & $95 \% \mathrm{Cl}$ \\
\hline \multirow[b]{2}{*}{ Gender } & Female & \multirow[b]{2}{*}{0.904} & \multirow[b]{2}{*}{0.001} & \multirow[b]{2}{*}{2.494} & \multirow[b]{2}{*}{$1.477-4.214$} \\
\hline & Male & & & & \\
\hline \multirow{2}{*}{ Self-report on use of medication } & Regular & \multirow{2}{*}{1.065} & \multirow{2}{*}{0.001} & \multirow{2}{*}{2.900} & \multirow{2}{*}{$1.508-5.577$} \\
\hline & Not regular & & & & \\
\hline Clinic attendance & Regular & 1.256 & $<0.001$ & 3.512 & $1.772-6.960$ \\
\hline \multirow{2}{*}{ Diabetes mellitus } & No & \multirow{2}{*}{1.996} & \multirow{2}{*}{$<0.001$} & \multirow{2}{*}{7.357} & \multirow{2}{*}{$3.190-16.966$} \\
\hline & Yes & & & & \\
\hline \multirow{3}{*}{ Clinic attended } & COOP & 0.455 & 0.167 & 1.576 & $0.826-3.007$ \\
\hline & NHIS & \multirow{2}{*}{0.366} & \multirow{2}{*}{0.235} & \multirow{2}{*}{1.441} & \multirow{2}{*}{$0.789-2.634$} \\
\hline & GOPC & & & & \\
\hline
\end{tabular}

The independent predictors of controlled BP after logistic regression analysis were female gender, regular use of medication, regular clinic attendance and absence of diabetes mellitus.

since clinic attendance ensures regular BP check and aggressive treatment by the managing physician in cases of uncontrolled BP. Owing to the asymptomatic nature of hypertension, patients tend to use the same anti-hypertensive drug prescribed earlier by the physician even in the face of poorly controlled BP. Regular clinic attendance detects uncontrolled BP and ensures appropriate management by the attending physician.

Absence of diabetes mellitus was also shown to be an independent predictor of controlled BP. This finding is similar to reports from other parts of Nigeria. ${ }^{7,9,27} \mathrm{~A}$ German study also reported that having diabetes mellitus was a negative determinant of controlled BP. ${ }^{23}$ Plausible reasons for this poor control rate in hypertensive patients with co-morbid diabetes mellitus might be due to microvascular and macrovascular complications seen in diabetes mellitus. The pill burden in such patients who require more drugs than patients who had only hypertension may be too much for these patients to follow especially if they have poor coping ability as a result of their disease. The high cost of multiple drugs is an additional burden, especially on the economically deprived patient. 
The finding of $18.4 \%$ control rate among participants who had diabetes mellitus in this study is low when compared with the $23.7 \%^{7}$ reported in Ilorin, Nigeria. A BP control target of $\leq 140 / 90 \mathrm{mmHg}$ used for diabetes mellitus patients in the later study might have contributed to the higher control rate documented. Studies using a BP goal of $<140 / 90 \mathrm{mmHg}$ in hypertensive people with diabetes mellitus might overestimate BP control rates. ${ }^{28,29}$ This study confirmed that achieving optimal BP control in hypertensive patients with co-morbid diabetes mellitus is often challenging and difficult as only a minority of patients with diabetes mellitus had their BP below the recommended goal. This observation reinforces the need for intensive BP control in diabetics.

The proportion of respondents who were enrolled in health insurance with controlled BP was greater compared with those who were not enrolled (51.7\% versus $43.8 \%$ ). A surprising finding in this study is the fact that enrolment in the National Health Insurance Scheme was not statistically significantly associated with BP control. While this agrees with the study by Hyman et al. $^{30}$ in the United States of America, which also found no association between BP control and health insurance, it is at variance with many studies that have consistently established a significant association between controlled BP and possession of health insurance..$^{21,22}$

Perhaps the failure of this study to find an association between BP control and health insurance might be as a result of the relatively small number of respondents with health insurance in the study population and consequently insufficient statistical power to detect a difference. Poor quality of health care from other factors such as physician inertia may also be responsible. The implication of the finding is that availability of highly subsidised drugs alone may not be enough to ensure compliance and improve control. Therefore, holistic care taking into cognisance patient-related factors, physician-related factors and support from the family is essential in hypertension management.

This study showed that patients' knowledge about hypertension did not seem to have a significant effect on BP control ( $p=0.093)$. Likewise, a Sudanese study ${ }^{31}$ showed that good patients' knowledge regarding the complications of hypertension did not correlate positively with BP control. This is not unexpected, as good knowledge may not translate to the right attitude and practice. Contrary to this study, other researchers have shown that patients' knowledge about hypertension was significantly related to the rate of $\mathrm{BP}$ control. ${ }^{32,33}$ The observed difference may be due to lack of a uniform standardised tool in assessing knowledge in patients with hypertension.

The failure of this study to find an association between BP control and the practice of exercise may be attributed to the fact that it might be a lot more difficult to see the effect of prevention than to see the effect of intervention as what respondents reported as adequate exercise may be inadequate. It is, however, worthy of mention that despite the fact that the practice of any form of exercise was self-reported, the proportion of respondents who practised any form of exercise was still small (36.9\%). Even among those who did practise any form of exercise, less than half of them did it at the recommended frequency ( $\geq 3$ days in a week and at least 30 minutes for each session). This was in consonance with a previous report by lloh et al., ${ }^{25}$ in 2014 , who found the adherence rate to physical activity to be the lowest among the domains of lifestyle modification assessed among adult hypertensive Nigerians with essential hypertension in Eastern Nigeria.
The practice of regular exercise has been shown to be suboptimal among hypertensives in Nigeria ${ }^{25,32}$ and other parts of the world. ${ }^{16}$ The obvious benefits of moderate-intensity exercise on BP control are documented ${ }^{16,34}$ but concerns regarding adherence are growing. ${ }^{25,32}$ The suboptimal practice of exercise among the respondents in this study suggests that primary care physicians must inculcate the habit of counselling hypertensive patients on the importance of regular exercise. They must also prescribe physical exercise in the same way as anti-hypertensive medications are prescribed. Also, patients must be followed up to make sure that they practise the prescribed physical activity in order to improve blood pressure control.

\section{Conclusion}

The percentage of hypertensive respondents with optimal BP control in this study is low, despite one-third of them having health insurance. Physicians should pay more attention to patients who are likely to have poor BP control. This includes being male, having coexisting diabetes mellitus, poor adherence to medication and poor clinic attendance. Furthermore, lifestyle modification as well as a $100 \%$ health insurance package for all levels of hypertensive care should be extended to the informal sector of the economy in order to increase access to quality health care.

\section{Limitations}

The following limitations were considered in this study. The limitations imposed by the self-reported measure of adherence are acknowledged by the authors. Second, the related data cannot address issues of causal relationship between blood pressure control and its determinants as a result of the crosssectional design of the study. Furthermore, some of the patients that were labelled as having primary hypertension might indeed have secondary hypertension. This could be avoided if facilities were readily available for extensive investigations. Lastly, the prevalence of diabetes mellitus did not include undiagnosed respondents.

Acknowledgement - The authors appreciate Mr Ogunlana of the Department of Physiotherapy, FMC, Abeokuta for his technical support. Special thanks are offered to all colleagues in Department of Family Medicine, FMCA, Abeokuta for their contributions during the preparation of this work. The authors also wish to express their gratitude to the Head of Department of Medical Records, FMC, Abeokuta.

Declaration - Ethical approval for the study was obtained from the Federal Medical Centre, Abeokuta ethical and research committee. Funding for the research was provided by the authors. There is no conflict of interest, as the authors have no financial or personal relationships that may have inappropriately influenced them in writing this paper.

Key messages - Health care providers should reflect on various factors affecting blood pressure control. This will help in the establishment of strategies with patients and family members so that control of blood pressure in patients with hypertension can be optimal and cost-effective.

\section{References}

1. Kearney PM, Whelton M, Reynolds K, et al. Worldwide prevalence of hypertension. J Hypertens. 2004;22(1):11-9.

2. Kearney PM, Whelton M, Reynolds $K$, et al. Global burden of hypertension: analysis of worldwide data. Lancet. 2005;365(9455):217-23. 
3. Mathers C, Stevens G, Mascarenhas M. Global health risks: Mortality and burden of disease attributable to selected major risks. Geneva: World Health Organization; 2009.

4. Ekere A, Yellowe B, Umune S. Mortality patterns in the accident and emergency department of an urban hospital in Nigeria. Niger J Clin Pract. 2005;8(1):14-8.

5. Bramlage $P$, Böhm $M$, Volpe $M$, et al. A Global perspective on blood pressure treatment and control in a referred cohort of hypertensive patients. J Clin Hypertens. 2010;12(9):666-77.

6. Akpa MR, Alasia D, Emem-Chioma P. An appraisal of hospital based blood pressure control in Port Harcourt, Nigeria. Nigerian Health J. 2008;8: 27-30.

7. Olanrewaju T, Aderibigbe A, Chijioke A, et al. Descriptive analysis of blood pressure control among treated hypertensive patients in a tertiary hospital in Nigeria. Afr J Med Med Sci. 2011;40(3):207-12.

8. Oyati Al, Orogade AA, Danbauchi SS, et al. Awareness, treatment and control of hypertension among hypertensives in Zaria. J Med Trop. 2011;13(2):139-44.

9. Tamuno I, Babashani M. Blood pressure control amongst hypertensive patients in a tertiary health care facility in Northern Nigeria. Res J Med Sci. 2012;6(1):26-32.

10. Iloh GU, Ofoedu JN, Njoku PU, et al. Medication adherence and blood pressure control amongst adults with primary hypertension attending a tertiary hospital primary care clinic in Eastern Nigeria: original research. Afr Prim Health Care Fam Med. 2013;5(1):1-6.

11. Awobusuyi J, Adebola A, Ajose F. Prevalence and socio-demographic profile of hypertensive patients in a Nigerian General Out-Patients' Department. Internet J Third World Med. 2012;10(1):1-9.

12. National Population Commission. National population census, 2006. Abuja: National Population Commission. 2006.

13. Araoye MO. Subject selection: sample size determination. In: MO Araoye, editor. Research methodology with statistics for health and social sciences, 1st ed. Ilorin: Nathadex; 2003. p. 117-18.

14. Alebiosu C, Raimi T, Ayodele O, et al. The impact of knowledge, attitude, practice and beliefs of hypertensives on drug compliance. Cardiol Trop. 2003;29(115):39-42.

15. Pickering TG, Hall JE, Appel LJ, et al. Recommendations for blood pressure measurement in humans and experimental animals: part 1: blood pressure measurement in humans: a statement for professionals from the subcommittee of professional and public education of the American Heart Association Council on High Blood Pressure Research. Hypertension. 2005;45:142-61.

16. Alsairafi M, Alshamali K, Al-rashed A. Effect of physical activity on controlling blood pressure among hypertensive patients from Mishref area of Kuwait. Eur J Gen Med. 2010;7(4):377-84.

17. Aram VC, George LB, Henry R, et al. The seventh report of the Joint National Committee on prevention, detection, evaluation, and treatment of high blood pressure: THE JNC 7 REPORT. JAMA. 2003;289(19):2560-72.

18. World Health Organization. Waist circumference and waist-hip ratio: report of a WHO expert consultation. Geneva: World Health Organization (WHO); 2008.
19. Salako B, Ajose F, Lawani E. Blood pressure control in a population where antihypertensives are given free. East Afr Med J. 2004;80(10):529-31.

20. Hendriks ME, Wit FW, Roos MT, et al. Hypertension in sub-Saharan Africa: Cross-sectional surveys in four rural and urban communities. PloS One. 2012;7(3):e1-e9.

21. Hendriks ME, Wit FW, Akande TM, et al. Effect of health insurance and facility quality improvement on blood pressure in adults with hypertension in Nigeria. JAMA Intern Med. 2014;174(4):555-63.

22. Kayima J, Wanyenze RK, Katamba A, et al. Hypertension awareness, treatment and control in Africa: a systematic review. BMC Cardiovasc Disord. 2013;13(1):1-11.

23. van den Berg N, Meinke-Franze C, Fiss T, et al. Prevalence and determinants of controlled hypertension in a German population cohort. BMC Public Health. 2013;13(1):594.

24. Egan BM, Zhao Y, Axon RN. US trends in prevalence, awareness, treatment, and control of hypertension, 1988-2008. JAMA. 2010;303(20):2043-50.

25. Iloh GUP, Amadi AN, Okafor GOC, et al. Adherence to lifestyle modifications among adult hypertensive Nigerians with essential hypertension in a primary care clinic of a tertiary hospital in resource-poor environment of Eastern Nigeria. Br J Med Med Res. 2014;4(18):3478-90.

26. World Health Organization. Adherence to long-term therapies: Evidence for action. Geneva: World Health Organization; 2003. WHO/ MNC/03.01; 2010.

27. Arije A, Kuti M, Fasanmade A, et al. Control of hypertension in Nigerians with diabetes mellitus: a report of the Ibadan Diabetic/ Kidney Disease Study Group. Int J Diabetes Metab. 2007;15:82-6.

28. Fields LE, Burt VL, Cutler JA, et al. The burden of adult hypertension in the United States 1999 to 2000: a rising tide. Hypertension. 2004;44(4):398-404.

29. He J, Muntner P, Chen J, et al. Factors associated with hypertension control in the general population of the United States. Arch Intern Med. 2002;162(9):1051-8.

30. Hyman DJ, Pavlik VN. Characteristics of patients with uncontrolled hypertension in the United States. N Engl J Med. 2001;345(7):479-86.

31. Osman E, Suleiman I, Elzubair A. Patients knowledge of hypertension and its control in Eastern Sudan. East Afr Med J. 2008;84(7):324-8.

32. Katibi I, Olarinoye J, Kuranga S. Knowledge and practice of hypertensive patients as seen in a tertiary hospital in the middle belt of Nigeria. Niger J Clin Pract. 2010;13(2):159-62.

33. Wang X, Bai H, Ma K, et al. Relationship between the patients knowledge on hypertension prevention and control and the rate on blood pressure control. Zhonghua liu xing bing xue za zhiZhonghua liuxingbingxue zazhi. 2003;24(12):1082-5.

34. Halm J, Amoako E. Physical activity recommendation for hypertension management: Does healthcare provider advice make a difference? Ethn Dis. 2007;18(3):278-82.

Received: 16-03-2016 Accepted: 25-04-2016 


\section{Appendix I}

\section{Informed Consent \\ Dear Sir/Madam,}

I hereby seek your consent to participate in this research.

I am a doctor at the Department of Family Medicine of a secondary care health centre. I intend to find out the pattern of blood pressure control and determine the factors affecting control of blood pressure in patients with essential hypertension with a view to improving control of blood pressure among patients with essential hypertension.

If you consent, a questionnaire will be administered to you followed by a physical examination. The procedure will last for about 20 minutes. The result of this project will be presented in a West African College of Physicians dissertation project.

Your participation is entirely of your own free will and you can withdraw from the study at any time you like without explanation. Refusal to participate in the study will not affect your treatment in any way. You have the right to refuse to answer any question you don't want to answer.

Please note that any information collected will remain confidential. Your name will not be attached to any published results. My supervising consultants and I will have access to the data.

Kindly indicate your decision by signing in the space below.

Thank you.

Date and signature or thumbprint of participant

Date and signature or thumbprint of witness

\section{Appendix II}

\section{Questionnaire}

RESEARCH PROFORMA ON AN APPRAISAL OF BLOOD PRESSURE CONTROL AND ITS DETERMINANTS AMONG PATIENTS WITH PRIMARY HYPERTENSION SEEN AT A PRIMARY CARE SETTING IN WESTERN NIGERIA.

Good day Sir/Madam,

Thank you for consenting to participate in this study. This research is about finding out the factors influencing blood pressure control. It will help us serve you better. Your cooperation is needed to truthfully answer the questions below. All information will be strictly confidential and it will take only a few minutes. Thank you.

Serial Number.

Hospital number.

Date

\section{A. SOCIO-DEMOGRAPHIC VARIABLES}

1) Age. years

2) Gender:(i) Male(ii) Female

3) Marital status:(i) Single(ii) Married(iii) Divorced

(iv) Separated(v) Widowed

4) Religion:(i) Islam(ii) Christianity(iii) Traditional belief

(iv) Others

5) Ethnic group:(i) Yoruba (ii) Hausa (iii) Igbo (iv) Others

6) Marriage type:(i) Monogamy(ii) Polygamy

7) If polygamy, number of wives

8) Household size 


\section{B. SOCIO-ECONOMIC DATA}

9) Level of education completed by subject: (i) No formal education(ii) Primary (iii) Secondary (iv) Tertiary

10) What do you do for a living? ...?

11) What is your average monthly income. ?...?

\section{SOCIAL HISTORY}

12) Are you currently smoking?(i) Yes(ii) No

13) Are you currently drinking alcohol? (i) Yes (ii) No

14) Do you exercise?(i) Yes(ii) No

15) If yes to question 26, which of these exercises do you do?

(i) Cycling (ii) Basketball (iii) Jogging (iv) Swimming(v) Soccer

(vi) Walking (fast)(vii) Others

16) How frequently do you do the exercise stated above?

(i) Every two weeks (ii) Once per week (iii) 1-2 days/ week (iv) $\geq 3$ days/ week

17) How long does the exercise last? (i) < 30minutes (ii) $>30$ minutes

\section{CLINICAL FACTORS}

18) How long ago were you diagnosed as hypertensive?

19) How long ago have you been on an antihypertensive?

20) How often do you take your drugs? (i) Regularly (ii) Not regularly

21) If not regularly, why?

(i) Often forget (ii) High cost of drugs (iii) Religious practices and cultural beliefs

(iv) Poor knowledge of disease and ignorance on long-term treatment (v) Use of alternative

therapy (vi) Adverse drug reaction (vii) Too many drugs (viii) Inadequate access to

medical care

22) Do you keep your clinic appointment? (i) Yes (ii) No

23) If no, why?

(i) Tight job schedule (ii) Long distance (iii) Financial reasons (iv) Other reasons

24) Do you have access to health care insurance? (i) Yes (ii) No

25) Is any member of your family hypertensive? (i) Yes (ii) No (iii) I don't know

26) If yes, state relationship to you.

27) Do you have diabetes?

28A) Knowledge on hypertension

\begin{tabular}{l} 
QUESTION ADEQUATE RESPONSE INADEQUATE RESPONSE \\
\hline What is hypertension? \\
What causes it? \\
Do you know the names of your drugs? \\
What is good blood pressure control? \\
What are the consequences of poor blood pressure control? \\
Do you think hypertension can be cured?
\end{tabular}


28B) What is the effect of any of these on blood pressure?

Increase

Decrease

Salt

Overweight

Exercise

Tobacco

Alcohol

\section{E. PHYSICAL EXAMINATION}

29) Systolic blood pressure

30) Diastolic blood pressure

31) Waist circumference $(\mathrm{cm})$ 